\title{
Utilization and prescribing patterns of direct oral anticoagulants
}

\author{
Maegan MWhitworth' \\ Krystal K Haase \\ David S Fike' \\ Ravindra M Bharadwaj \\ Rodney B Young 3 \\ Eric J MacLaughlin 1,4 \\ 'Department of Pharmacy Practice, \\ Texas Tech University Health \\ Sciences Center (TTUHSC) School \\ of Pharmacy, ${ }^{2}$ Department of \\ Internal Medicine, ${ }^{3}$ Department of \\ Family and Community Medicine, \\ ${ }^{4}$ Departments of Family Medicine and \\ Internal Medicine, TTUHSC School of \\ Medicine, Amarillo, TX, USA
}

\section{Video abstract}

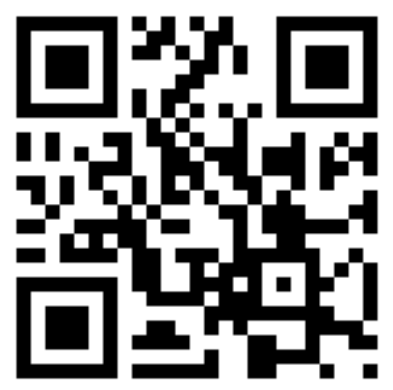

Point your SmartPhone at the code above. If you have a QR code reader the video abstract will appear. Or use: http://youtu.be/0QnFaOtal I4

Correspondence: Eric J MacLaughlin Department of Pharmacy Practice, Texas Tech University Health Sciences Center (TTUHSC) School of Pharmacy, I300 S. Coulter Street, Suite 203, Amarillo, TX 79106, USA

Tel + I $8064 \mid 49302$

Fax + I 8063564018

Email Eric.MacLaughlin@TTUHSC.EDU
This article was published in the following Dove Press journal:

International Journal of General Medicine

10 March 2017

Number of times this article has been viewed

Background: Scant literature exists evaluating utilization patterns for direct oral anticoagulants (DOACs).

Objectives: The primary objective was to assess DOAC prescribing in patients with venous thromboembolism (VTE) and nonvalvular atrial fibrillation (NVAF) in outpatient clinics. Secondary objectives were to compare utilization between family medicine (FM) and internal medicine (IM) clinics, characterize potentially inappropriate use, and identify factors associated with adverse events (AEs).

Methods: This was a retrospective cohort study of adults with NVAF or VTE who received a DOAC at FM or IM clinics between 10/19/2010 and 10/23/2014. Descriptive statistics were utilized for the primary aim. Fisher's exact test was used to evaluate differences in prescribing using an adapted medication appropriateness index. Logistic regression evaluated factors associated with inappropriate use and AEs.

Results: One-hundred twenty patients were evaluated. At least 1 inappropriate criterion was met in 72 patients $(60.0 \%)$. The most frequent inappropriate criteria were dosage $(33.0 \%)$, duration of therapy (18.4\%), and correct administration (18.0\%). Apixaban was dosed inappropriately most frequently. There was no difference in dosing appropriateness between FM and IM clinics. The odds of inappropriate choice were lower with apixaban compared to other DOACs (odds ratio $[\mathrm{OR}]=0.088 ; 95 \%$ confidence interval $[\mathrm{CI}] 0.008-0.964 ; p=0.047$ ). Twenty-seven patients (22.5\%) experienced an AE while on a DOAC, and the odds of bleeding doubled with each inappropriate criterion met (OR=1.949; 95\% CI 1.190-3.190; $p=0.008)$.

Conclusion: Potentially inappropriate prescribing of DOACs is frequent with the most common errors being dosing, administration, and duration of therapy. These results underscore the importance of prescriber education regarding the appropriate use and management of DOACs. Keywords: rivaroxaban, dabigatran, apixaban, atrial fibrillation, venous thromboembolism, medication errors

\section{Introduction}

Thromboembolic events are major causes of morbidity and mortality in the United States (US). Atrial fibrillation, which is associated with a 5-fold increase in the risk of cardioembolic stroke, is a leading cause of death and permanent disability. ${ }^{1-3}$ Venous thromboembolism (VTE), including deep vein thrombosis (DVT) and pulmonary embolism (PE), are likewise a significant cause of mortality, with an estimated prevalence of over 100,000 per year. ${ }^{4}$ The health care costs associated with VTE are considerable, exceeding $\$ 1.5$ billion annually in the US. ${ }^{5,6}$

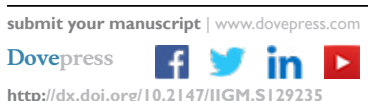

http://dx.doi.org/10.21471UGM.S129235 
Historically, anticoagulant therapy with warfarin has been considered the standard of care for prevention of thromboembolic events associated with VTE and atrial fibrillation. ${ }^{3,7}$ Physician familiarity, clinical experience, and efficacy continue to influence prescribing patterns of warfarin. In addition, the ability to monitor the degree of anticoagulation, reversibility of effects, and low-cost generic availability appeal to both patients and providers. However, several disadvantages exist for use of warfarin including significant drug-drug and drug-food interactions, delayed onset and offset of action, complex dosing with genetic variances, narrow therapeutic index, and frequent monitoring with patient-specific dose adjustments. ${ }^{3,4,8-11}$ Despite demonstrated efficacy in preventing thrombotic disease, the practical challenges associated with the utilization of warfarin have led to the search for new treatment options. ${ }^{3}$

Direct oral anticoagulants (DOACs), such as dabigatran, rivaroxaban, and apixaban, are newer agents approved for prevention of thrombosis in both nonvalvular atrial fibrillation (NVAF) and VTE. Randomized controlled trials have demonstrated non-inferiority to warfarin in preventing thromboembolic events. ${ }^{12-14}$ Advantages of these newer agents compared to warfarin include no routine monitoring of anticoagulant effect due to more predictable pharmacological profiles, fewer drug-drug and drug-food interactions, and no required bridge therapy during brief interruptions due to rapid onset and offset of action. ${ }^{8-10}$ Challenges associated with DOACs include lack of clinical experience, concerns related to safety considering no antidote is available for reversal of anticoagulant effects for most agents, and cost. Furthermore, strict adherence is crucial as missed doses greatly increase the risk of thromboembolism due to a much shorter half-life compared to warfarin. ${ }^{3,4,8-10,15}$

Current guidelines support the use of DOACs for patients with DVT, PE, and NVAF and a $\mathrm{CHA}_{2} \mathrm{DS}_{2}$-VASc score of 2 or greater (level B recommendation). ${ }^{8-11,15}$ They are also recommended for patients unable to maintain therapeutic international normalization ratio (INR) levels with warfarin therapy. Before initiation of any DOAC, it is recommended that kidney function be evaluated to determine if dose reductions are indicated. ${ }^{15}$

Although DOACs have provided possible solutions to several challenges associated with warfarin therapy, some prescribers remain unaware of potential drug-drug interactions, dose adjustments based on kidney function, and cost implications. Current literature evaluating the utilization, prescribing patterns, and appropriateness of dabigatran and rivaroxaban in patients greater than 65 years of age with atrial fibrillation have indicated a high prevalence of inappropriate prescribing, which may lead to adverse events (AEs). ${ }^{16-18}$ However, literature evaluating prescribing of all DOACs for patients with either atrial fibrillation or DVT/PE is lacking. Therefore, determining the utilization and prescribing patterns of DOACs within a broader patient population could have a positive impact on patient outcomes and overall health costs.

The primary aim of this study was to assess utilization and prescribing patterns of DOACs in patients with NVAF and VTE (ie, PE and DVT) in an outpatient practice setting. Secondary aims of this study were to determine if differences exist in utilization and prescribing patterns of DOACs between internal medicine (IM) and family medicine (FM) teaching clinics, characterize potentially inappropriate prescribing based on drug interactions, contraindications, dosing, cost/access to treatment, and identify factors (eg, inappropriate prescribing, kidney function, age, agent selection) associated with undesirable treatment outcomes.

\section{Methods}

\section{Study design and patients}

This was a retrospective, cohort analysis of adults receiving a DOAC with a diagnosis of NVAF or VTE. Patients were identified through a query of outpatient FM and IM clinic medical records and confirmed by manual chart review. Patients were eligible for inclusion if the following criteria were met: 18 years of age or greater, diagnosis of NVAF, PE, or DVT (based on ICD-9 codes), documented clinic visit with FM or IM from 10/19/2010 to 10/23/2014, and documented prescription for dabigatran, rivaroxaban, or apixaban as anticoagulant therapy for prevention or treatment of thrombosis. Patients were excluded if they were less than 18 years of age, pregnant, or had inadequate documentation in the medical record to meet inclusion criteria.

\section{Data collection}

All patient data were maintained in a Microsoft Excel (Redmond, WA, USA) spreadsheet. To provide quality assurance, individuals responsible for collecting data were trained in the use of the database and random audits were conducted. Baseline demographics collected included age, race, sex, height, weight, body mass index, relevant past medical history, insurance status, indication(s) for anticoagulant therapy, prescriber specialty (FM vs IM), prescriber status (resident, faculty, or midlevel [ie, nurse practitioner or physician assistant]), and 
atrial fibrillation thromboembolic risk scores $\mathrm{CHADS}_{2}$ and $\mathrm{CHA}_{2} \mathrm{DS}_{2}$-VASc. Additional data obtained from subject medical records included laboratory markers to evaluate kidney function (ie, calculated creatinine clearance $[\mathrm{CrCl}]$ using the Cockcroft-Gault equation), concomitant medications, duration of anticoagulant therapy, drug-drug or drug-disease interactions, and history of anticoagulant and antiplatelet therapy. If subjects were transitioned between anticoagulants within the study period, the most recent DOAC data were utilized. Inpatient and outpatient records were evaluated to identify AEs (eg, hemorrhagic and/or thrombotic events), hospital admissions, or emergency room visits related to anticoagulant use during the study period. Finally, an adapted medication appropriateness index (MAI) tool was utilized to evaluate inappropriate prescribing. The MAI is a comprehensive tool that has been previously validated in the elderly population to assess inappropriate prescribing of medications. ${ }^{19,20}$ For this study, a similar methodology to Larock et al was utilized. ${ }^{18}$ It included an adapted MAI for DOAC prescribing with 9 categories of appropriateness: indication, choice, dosage, modalities and practicability of administration, drug-drug interactions, drug-disease interactions, duplication, and duration. Each MAI criterion was evaluated using detailed instructions that were developed based on US Food and Drug Administration (FDA)-approved DOAC prescribing information and guideline recommendations (Table S1). For each criterion, the evaluator rated A (appropriate), B (inappropriate with limited clinical importance), or C (inappropriate). Only inappropriate ratings (C) were considered for the primary outcome. The study was approved by the Texas Tech University Health Sciences Center Institutional Review Board and patient consent was not required.

\section{Statistical analysis}

Patient data were converted from Microsoft Excel to IBM SPSS 23 (IBM Corp, Armonk, NY, USA) for analysis. Descriptive statistics, including means, standard deviations, and percentages were generated for the sample. Fisher's exact test was used to assess the association of categorical variables. Binary logistic regression was implemented to determine the relationship of continuous and dichotomous independent variables with dichotomous dependent variables. Categorical independent variables used in the logistic regression models were dummy coded prior to analysis. For the logistic regression models, goodness of fit was assessed and residuals were reviewed. For all analyses, the a priori level of significance was .05 .

\section{Results}

From 10/19/2010 to $10 / 23 / 2014,146$ patients were identified for possible inclusion. A total of 26 patients were excluded due to lack of indication (NVAF or VTE) for a DOAC, leaving a study population of 120 patients. Baseline demographics are depicted in Table 1.

Of the 120 patients included in the analysis, 40 patients $(62.5 \%)$ with NVAF met at least 1 inappropriate criterion compared to $35(58.3 \%)$ with VTE. Rivaroxaban was the most commonly prescribed DOAC received by $56 \%$ of patients. Dabigatran and apixaban were prescribed in $34 \%$ and $10 \%$ of patients, respectively. At least 1 inappropriate criterion was observed in 72 patients $(60.0 \%)$. Thirty-six patients $(30.0 \%)$ met 1 inappropriate criterion, 23 (19\%) had 2 inappropriate criteria, 9 (7.5\%) had 3 inappropriate criteria, and 4 (3.3\%) met 4 out of 9 inappropriate criteria. Figure 1 describes the rate of inappropriateness per criterion. The 3 most common inappropriate categories were dosage $(33 \%)$, duration of therapy (18.4\%), and correct administration (18\%).

For patients in whom inappropriate dosing was noted $(\mathrm{n}=39 ; 33.3 \%)$, most were associated with apixaban $(\mathrm{n}=5$; $41.7 \%)$, followed by dabigatran $(n=11 ; 28.2 \%)$ and rivaroxaban $(n=23 ; 34.8 \%)$. No difference was found between FM and IM clinics within the most prevalent category, inappropriate dosage $(n=16 ; 35.6 \%$ vs $n=23 ; 31.9 \%, p=0.840)$. Additionally, differences in kidney function did not confer a difference in appropriateness of dose prescribed $(37.5 \%$ when $\mathrm{CrCl}$ $<60 \mathrm{~mL} / \mathrm{min}$ vs $31.1 \%$ when $\mathrm{CrCl} \geq 60 \mathrm{~mL} / \mathrm{min} ; p=0.544)$.

Table I Baseline demographics $(n=120)$

\begin{tabular}{lll}
\hline Characteristic & $\begin{array}{l}\text { Family medicine } \\
\text { clinic }(\mathbf{n = 4 7})\end{array}$ & $\begin{array}{l}\text { Internal medicine } \\
\text { clinic }(\mathbf{n}=\mathbf{7 3})\end{array}$ \\
\hline $\begin{array}{l}\text { Age (years; mean } \pm \text { SD) } \\
\text { Sex }\end{array}$ & $66.2 \pm 18.5$ & $65.6 \pm 17.8$ \\
$\quad$ Male (\%) & 36.2 & 50.7 \\
Race & & \\
$\quad$ Caucasian (\%) & 95.7 & 83.6 \\
Insured (\%) & 80.9 & 68.5 \\
Wt (kg; median, range) & $82.8(42.0-194.5)$ & $79.8(47.7-165.0)$ \\
BMI (mean \pm SD) & $32.4 \pm 10.8$ & $29.8 \pm 8.77$ \\
CrCl (mean \pm SD) & $73.0 \pm 39.4$ & $73.2 \pm 35.4$ \\
Medical history (\%) & & \\
Stroke & 4.3 & 16.4 \\
Heart failure & 3.62 & 24.7 \\
Hypertension & 80.9 & 68.5 \\
Diabetes & 29.8 & 16.5 \\
$\quad$ Vascular disease & 21.3 & 36.9 \\
CHA DS - -VASc & $4 \pm 1.12$ & $4 \pm 1.64$ \\
\hline
\end{tabular}

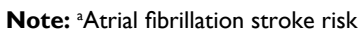

Abbreviations: $\mathrm{BMI}$, body mass index; $\mathrm{CrCl}$, creatinine clearance; SD, standard deviation; $\mathrm{Wt}$, weight. 


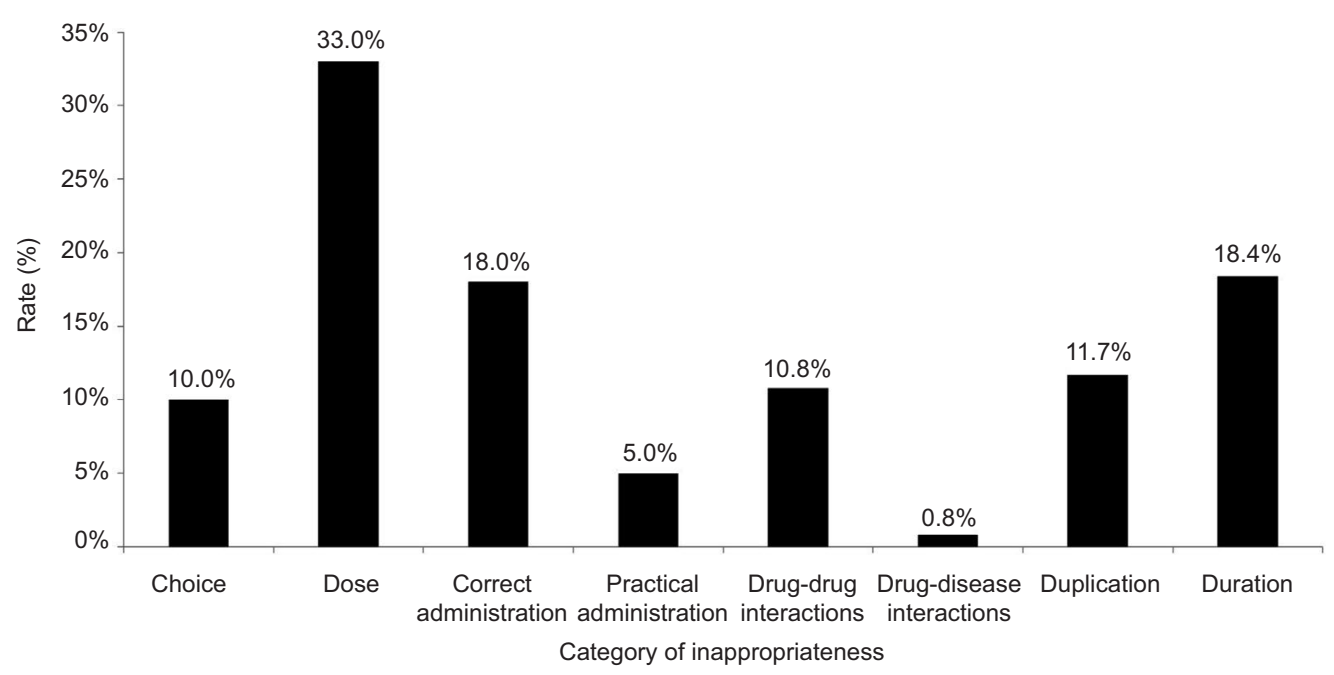

Figure I Rate of inappropriateness by category.

Results from the logistic regression analysis are shown in Tables 2 and 3. Two statistically significant predictors of appropriate choice of DOAC utilization over vitamin $\mathrm{K}$ antagonist were identified. Patients with prescription insurance had approximately 6 times the odds of appropriately receiving a DOAC compared to those without prescription insurance (adjusted odds ratio $[\mathrm{OR}]=6.298 ; 95 \%$ confidence interval [CI] 1.112-35.658; $p=0.038$ ). Additionally, the model suggested that patients prescribed apixaban had a much lower odds of meeting appropriate choice criterion compared to those receiving rivaroxaban (adjusted $\mathrm{OR}=0.088 ; 95 \% \mathrm{CI}$ $0.008-0.964 ; p=0.047)$. Further analysis indicated patients with a history of bleeding were more likely to meet 1 or more categories of inappropriateness compared to those without a previous bleeding event ( $86 \%$ vs $57 \%$, respectively; $p=0.037$ ).

An AE was noted in 27 patients (22.5\%), among whom 20 patients (16.7\%) experienced a bleeding event, 4 (3.4\%) suffered from a thrombotic event (stroke or VTE), and 3 $(2.5 \%)$ had a non-thrombotic or non-bleeding event while

Table 2 Appropriateness of DOAC choice logistic regression

\begin{tabular}{llll}
\hline & $\begin{array}{l}\text { Adjusted odds } \\
\text { ratio (OR) }\end{array}$ & $\begin{array}{l}\text { 95\% confidence } \\
\text { interval }(\mathbf{C l})\end{array}$ & p-value \\
\hline $\mathrm{CrCl}$ & 1.016 & $0.982-1.05 \mathrm{I}$ & 0.360 \\
Family medicine & 0.113 & $0.007-1.848$ & 0.126 \\
Internal medicine & 0.112 & $0.006-2.035$ & 0.139 \\
$\mathrm{Rx}$ insurance & 6.298 & $1.112-35.658$ & 0.038 \\
Dabigatran & 1.638 & $0.238-11.289$ & 0.616 \\
Apixaban & 0.088 & $0.008-0.964$ & 0.047 \\
White & 3.595 & $0.428-30.202$ & 0.239 \\
Obese & 1.802 & $0.298-10.88 \mathrm{I}$ & 0.521 \\
Age $\geq 60$ years & 2.354 & $0.222-24.986$ & 0.477 \\
\hline
\end{tabular}

Abbreviations: $\mathrm{CrCl}$, creatinine clearance; DOAC, direct oral anticoagulant; $\mathrm{Rx}$ insurance, prescription insurance.
Table 3 Bleeding adverse events logistic regression

\begin{tabular}{llll}
\hline & $\begin{array}{l}\text { Adjusted odds } \\
\text { ratio (OR) }\end{array}$ & $\begin{array}{l}\text { 95\% confidence } \\
\text { interval }(\mathbf{C l})\end{array}$ & p-value \\
\hline Inappropriate count $^{\mathrm{a}}$ & 1.949 & $1.190-3.190$ & 0.008 \\
Age $\geq 60$ years & 9.078 & $1.010-81.603$ & 0.049 \\
Calculated $\mathrm{CrCl}$ & 1.028 & $1.001-1.055$ & 0.043 \\
Family medicine & 1.089 & $0.228-5.199$ & 0.915 \\
Internal medicine & 0.556 & $0.120-2.587$ & 0.454 \\
Rx insurance & 0.768 & $0.224-2.635$ & 0.675 \\
Dabigatran & 0.762 & $0.215-2.699$ & 0.673 \\
Apixaban & 0.425 & $0.038-4.806$ & 0.489 \\
White & 0.714 & $0.090-5.661$ & 0.750 \\
BMI & 0.927 & $0.839-1.023$ & 0.132 \\
\hline Note: &
\end{tabular}

Note: alnappropriate count, number of inappropriate categories met. Abbreviations: $\mathrm{BMI}$, body mass index; $\mathrm{CrCl}$, creatinine clearance; $\mathrm{Rx}$ insurance, prescription insurance.

taking a DOAC. According to the logistic regression model (Table 3), significant predictors of a bleeding AE include number of inappropriate criteria met, age $>60$ years, and calculated $\mathrm{CrCl}$. The analysis suggests that after controlling for covariates, the odds of a bleeding event roughly doubled with each additional inappropriate criterion met $(\mathrm{OR}=1.949$; 95\% CI 1.190-3.190; $p=0.008$ ). Additional analysis suggested that patients with a history of bleeding were more likely to experience a bleeding AE compared to those without a prior bleeding event ( $36 \%$ vs $14 \%$, respectively; $p=0.042$ ).

\section{Discussion}

The current study found a high degree of potentially inappropriate prescribing of DOACs in primary care teaching clinics. Almost two-thirds of patients met at least 1 potentially inappropriate criterion. The most common issues noted in prescribing were dosage, correct administration, and duration of therapy. 
Findings of our study are consistent with previously published literature ${ }^{18}$ although there are some notable differences. First, we did not consider the choice of a DOAC compared to warfarin inappropriate based on extreme weight (ie, $<50$ and $>110-120 \mathrm{~kg}$ ) due to lack of a specific contraindication in the approved package labeling. While extremes in weight may present challenges regarding the predictability of anticoagulation activity, and many prescribers prefer not to use DOACs in these populations, there are currently no differences in dosing in the package insert based solely on weight. ${ }^{21-23}$ In our study, approximately one-fifth of the subjects who received a DOAC weighed $>110 \mathrm{~kg}$, and of these, 2 had an AE (1 on dabigatran suffered a major bleed and 1 on rivaroxaban had a stroke/transient ischemic attack). In a study that assessed the safety, tolerability, pharmacokinetics, and pharmacodynamics of rivaroxaban in subjects of normal weight (70-80 kg) compared to subjects with extreme body weight ( $<50$ and $>120 \mathrm{~kg}$ ), no differences were found. ${ }^{24}$ Scant literature is available assessing safety and efficacy in patients with low weight. Further studies are needed to evaluate the use of DOACs in patient populations with extremes in weight.

Regarding dosing of DOACs, our study found a 33\% rate of inappropriate dosing. These findings are similar to a recent analysis of apixaban and rivaroxaban prescriptions written by US cardiologists, where a high percentage $(\sim 20 \%)$ was written for a reduced dose. ${ }^{25}$ Our findings of rivaroxaban being more frequently dosed lower than current prescribing recommendations are likewise consistent with their findings. Apixaban was more frequently dosed inappropriately compared to other DOACs, with most events comprising doses lower than the FDA-approved prescribing recommendations. This result may be due to the complexity of recommended kidney function dose adjustments associated with apixaban, which requires an evaluation of serum creatinine, weight, and age compared to simply calculating $\mathrm{CrCl}$ with other DOACs. Caution should be exercised when prescribing DOACs, and particular care should be taken regarding the dose used in patients with kidney dysfunction. In our study, the risk of bleeding was increased in patients with higher $\mathrm{CrCl}$, contrary to what one would expect. However, given the adjusted odds ratio (1.028), this may be of limited clinical relevance. In addition to dosage, the correct administration was also frequently inappropriate. Issues related to administration could be explained by differing dosing regimens based on the indication, agent, or patient demographics. Some prescribers reported patients taking dabigatran only once daily despite being prescribed twice daily.
Duration of therapy was commonly potentially inappropriate $(18.4 \%)$, with most prescribers extending anticoagulant therapy beyond recommendations for VTE. Recommendations included in the MAI used to evaluate the appropriateness of duration were obtained from manufacturers' labeled indications and evidence-based guidelines. Our results suggest that some prescribers are uncomfortable following CHEST guidelines for length of DOAC therapy after a VTE event and prolonged therapy. ${ }^{8-10}$ While this practice may be suitable in various patient scenarios, a thorough risk-benefit analysis should be performed, along with a joint prescriber-patient discussion and detailed documentation. Alternatively, inappropriate duration of therapy could have been unintentional with poor documentation of DOAC start date, targeted duration of therapy not clearly stated in initial or follow-up care plan, or due to loss of follow-up.

According to our logistic regression, significant predictors of a bleeding $\mathrm{AE}$ were the number of inappropriate criteria met, age greater than or equal to 60 years, and calculated $\mathrm{CrCl}$. While increasing age and impaired kidney function are primarily fixed risk factors associated with increased bleeding with anticoagulants, appropriate patient selection and dosing are modifiable factors that could be improved through specific educational and practice initiatives. In addition, patients with a history of prior bleed were significantly associated with more categories of inappropriateness and greater incidence of a bleeding AE. These patients should be identified early and closely monitored for the duration of DOAC therapy. Thromboembolic event rates were low and thus excluded from analysis.

While the current study provides additional data related to factors associated with potentially inappropriate DOAC prescribing and variables that may increase this risk, there are limitations. First, the study is retrospective with a relatively small sample size. Thus, it was difficult for co-investigators to assess patient compliance with the DOACs, which may have impacted the observed results. However, it did evaluate use in 2 different clinics and is the first study evaluating multiple categories of appropriateness for the 3 DOACs currently commercially available. Secondly, although explicit instructions were provided for each category within the MAI, the evaluation of appropriateness could be viewed as subjective, especially in situations where clear evidence-based guideline recommendations were lacking. However, when questions arose related to appropriateness in a particular case, coinvestigators were queried to ascertain agreement, thereby decreasing this effect. Third, due to the retrospective nature of this study, our results may be confounded by inaccurate 
or incomplete documentation. This limitation was mitigated by verifying data with multiple sources, such as reviewing both outpatient and inpatient records for documentation of an AE. Finally, investigators noted that a large volume of DOAC prescribing (21.7\%) was performed by outside providers or consultants (eg, cardiologists). In these cases, patients were seen at FM and IM clinics for their primary care, but anticoagulation therapy may have either been started or managed by specialists. Therefore, the primary care provider may have been reluctant to change therapy. Nevertheless, the investigators chose to preserve these data when analyzing utilization, as appropriate use of pharmacotherapy is a shared responsibility.

Our results suggest several challenges associated with DOACs. First, strict adherence is critical, even compared to warfarin, due to differences in the pharmacokinetic and pharmacodynamic profiles. Adherence to medication declines when comparing once-daily to more frequent administration. Therefore, the fact that 2 DOACs are dosed twice daily may be a likely source of confusion among prescribers leading to inappropriate dosing. Additionally, marketing strategies that emphasize DOACs as a "simple" alternative to warfarin do not take into account the real-world challenge for providers to remember precise prescribing details, contraindications and precautions, and required dose adjustments.

Improvements in clinical decision support and expansion of the pharmacist's role in prescribing and utilization of DOACs may help address many of the challenges associated with their use. Clinical decision support tools provided in electronic medical records could be developed to detect potential medication inappropriateness. Likewise, the involvement of a clinical pharmacist in the care of patients on DOACs could also improve their use. A pharmacist may be more likely to have expertise in the medication and guidelines for their use, the time to focus specifically on drug therapy management and educating the patient rather than multiple competing issues that a patient may have, and can assist in transitions of care and communication with the patient's other health care providers.

\section{Conclusion}

An evaluation of the utilization of DOACs in patients with NVAF and VTE within outpatient clinic settings suggests frequent potentially inappropriate prescribing, which may lead to increased AEs, such as bleeding. These results underscore the importance of prescriber education regarding appropriateness, dosing, and monitoring of these agents. Additional research is needed to identify effective interventions to reduce the likelihood of potentially inappropriate prescribing and resultant adverse sequelae.

\section{Acknowledgment}

The authors would like to acknowledge Jacy Hodges, Pharm.D., who was a doctor of pharmacy student at the time the research was conducted and who assisted with data acquisition.

\section{Disclosure}

This works was presented as a poster (Abst. \#383) at the American College of Clinical Pharmacy Global Conference, San Francisco, CA, 10/20/2015. The authors report no other conflicts of interest in this work.

\section{References}

1. Chugh SS, Havmoeller R, Narayanan K, et al. Worldwide epidemiology of atrial fibrillation: a Global Burden of Disease 2010 Study. Circulation. 2014;129(8):837-847.

2. Wolf PA, Abbott RD, Kannel WB. Atrial fibrillation as an independent risk factor for stroke: the Framingham Study. Stroke. 1991;22(8): 983-988.

3. Kirley K, Qato DM, Kornfield R, Stafford RS, Alexander GC. National trends in oral anticoagulant use in the United States, 2007 to 2011. Circ Cardiovasc Qual Outcomes. 2012;5(5):615-621.

4. Hellwig T, Gulseth M. New oral therapies for the prevention and treatment of venous thromboembolism. Am J Health Syst Pharm. 2013;70(2): 113-125.

5. Dobesh PP. Economic burden of venous thromboembolism in hospitalized patients. Pharmacotherapy. 2009;29(8):943-953.

6. Office of the Surgeon General. The Surgeon General's Call to Action to Prevent Deep Vein Thrombosis and Pulmonary Embolism. Rockville, MD: Office of the Surgeon General; 2008. Available from: http://www. ncbi.nlm.nih.gov/books/NBK44178/.

7. Mueller RL, Scheidt S. History of drugs for thrombotic disease. Discovery, development, and directions for the future. Circulation. 1994;89(1): 432-449.

8. Ageno W, Gallus AS, Wittkowsky A, Crowther M, Hylek EM, Palareti G; American College of Chest Physicians. Oral anticoagulant therapy: Antithrombotic Therapy and Prevention of Thrombosis, 9th ed: American College of Chest Physicians Evidence-Based Clinical Practice Guidelines. Chest. 2012;141(2 Suppl):e44S-e88S.

9. You JJ, Singer DE, Howard PA, et al; American College of Chest Physicians. Antithrombotic therapy for atrial fibrillation: Antithrombotic Therapy and Prevention of Thrombosis, 9th ed: American College of Chest Physicians Evidence-Based Clinical Practice Guidelines. Chest. 2012;141(2 Suppl):e531S-e575S.

10. Kearon C, Akl EA, Ornelas J, et al. Antithrombotic therapy for VTE disease: CHEST guideline and expert panel report. Chest. 2016;149(2): $315-352$.

11. Holbrook A, Schulman S, Witt DM, et al; American College of Chest Physicians. Evidence-based management of anticoagulant therapy: Antithrombotic Therapy and Prevention of Thrombosis, 9th ed: American College of Chest Physicians Evidence-Based Clinical Practice Guidelines. Chest. 2012;141(2 Suppl):e152S-e184S.

12. Granger CB, Alexander JH, McMurray JJ, et al; ARISTOTLE Committees and Investigators. Apixaban versus warfarin in patients with atrial fibrillation. N Engl J Med. 2011;365(11):981-992.

13. Connolly SJ, Ezekowitz MD, Yusuf S, et al; RE-LY Steering Committee and Investigators. Dabigatran versus warfarin in patients with atrial fibrillation. N Engl J Med. 2009;361(12):1139-1151. 
14. Investigators $\mathrm{E}$, Bauersachs $\mathrm{R}$, Berkowitz $\mathrm{SD}$, et al. Oral rivaroxaban for symptomatic venous thromboembolism. N Engl J Med. 2010;363(26): 2499-2510.

15. January CT, Wann LS, Alpert JS, et al; American College of Cardiology/ American Heart Association Task Force on Practice Guidelines. 2014 AHA/ACC/HRS guideline for the management of patients with atrial fibrillation: a report of the American College of Cardiology/American Heart Association Task Force on Practice Guidelines and the Heart Rhythm Society. J Am Coll Cardiol. 2014;64(21):e1-e76.

16. Huang C, Siu M, Vu L, Wong S, Shin J. Factors influencing doctors' selection of dabigatran in non-valvular atrial fibrillation. J Eval Clin Pract. 2013;19(5):938-943.

17. Carley B, Griesbach S, Larson T, Krueger K. Assessment of dabigatran utilization and prescribing patterns for atrial fibrillation in a physician group practice setting. Am J Cardiol. 2014;113(4):650-654.

18. Larock AS, Mullier F, Sennesael AL, et al. Appropriateness of prescribing dabigatran etexilate and rivaroxaban in patients with nonvalvular atrial fibrillation: a prospective study. Ann Pharmacother. 2014; 48(10):1258-1268.
19. Spinewine A, Swine C, Dhillon S, et al. Effect of a collaborative approach on the quality of prescribing for geriatric inpatients: a randomized, controlled trial. J Am Geriatri Soc. 2007;55(5):658-665.

20. Spinewine A, Dumont C, Mallet L, Swine C. Medication appropriateness index: reliability and recommendations for future use. J Am Geriatr Soc. 2006;54(4):720-722.

21. Eliquis [package insert]. Princeton, NJ: Bristol-Myers Squibb Company; 2016.

22. Pradaxa [package insert]. Ridgefield, CT: Boehringer Ingelheim Pharmaceuticals, Inc; 2015.

23. Xarelto [package insert]. Titusville, NJ: Janssen Pharmaceuticals, Inc; 2016.

24. Kubitza D, Becka M, Voith B, Zuehlsdorf M, Wensing G. Safety, pharmacodynamics, and pharmacokinetics of single doses of BAY 59-7939, an oral, direct factor Xa inhibitor. Clin Pharmacol Ther. 2005;78(4): 412-421.

25. Nguyen E, White CM, Patel MR, et al. Doses of apixaban and rivaroxaban prescribed in real-world United States cardiology practices compared to registration trials. Curr Med Res Opin. 2016;32(7):1277-1279. 


\section{Supplementary material}

Table SI Adapted medication appropriateness index ${ }^{\mathrm{a}}$

\begin{tabular}{|c|c|c|}
\hline Criteria & Category & Instructions \\
\hline \multirow[t]{3}{*}{ Indication } & $\mathbf{A}$ & Valid indication exists \\
\hline & B & DOAC used as a last resort or indication does not fit within reimbursement criteria \\
\hline & C & Off-label use \\
\hline \multirow[t]{3}{*}{ Choice } & A & $\begin{array}{l}\text { DOAC preferred choice: labile INR with VKA, Cl to VKA, patient preference, recurrent } \\
\text { stroke/VTE on VKA, resistance to VKA }\end{array}$ \\
\hline & B & No contraindication, not yet tested, no recurrent stroke/VTE on VKA \\
\hline & C & $\begin{array}{l}\text { Not preferred choice: severe renal insufficiency, poor compliance, need for drug monitoring, } \\
\text { severe hepatic impairment, recurrent VTE/stroke on current DOAC }\end{array}$ \\
\hline \multirow[t]{2}{*}{ Dosage } & A & Receives daily dose as recommended \\
\hline & C & Inappropriate daily dose (too low or too high) \\
\hline \multirow[t]{3}{*}{ Correct administration } & $\mathbf{A}$ & Correct modalities of DOAC intake \\
\hline & B & $\begin{array}{l}\text { Limited clinical relevance for modalities of DOAC intake (rivaroxaban taken in evening, } \\
\text { dabigatran taken c/o meals) }\end{array}$ \\
\hline & C & $\begin{array}{l}\text { Inappropriate modalities of DOAC intake (once-daily dabigatran, variable times of intake, } \\
\text { rivaroxaban taken without meals) }\end{array}$ \\
\hline \multirow[t]{2}{*}{ Practical administration } & $\mathbf{A}$ & No difficult taking dosage form \\
\hline & C & $\begin{array}{l}\text { Difficulties taking the drug (dabigatran BID in patients with poor compliance, dabigatran in } \\
\text { patients with swallowing difficulties [capsules cannot be opened]) }\end{array}$ \\
\hline \multirow[t]{3}{*}{ Drug-drug interactions } & $\mathbf{A}$ & No DDI \\
\hline & B & Potential DDI (caution or warning) without s/sx adverse event \\
\hline & C & DDI contraindication with adverse consequence \\
\hline \multirow[t]{3}{*}{ Drug-disease interactions } & $\mathbf{A}$ & No drug-disease interactions \\
\hline & B & Potential interaction (caution or warning) without $s / s x$ of worsening disease \\
\hline & C & $\begin{array}{l}\text { Contraindicated with disease, presents high risk, or DOAC used with caution and positive s/sx } \\
\text { of worsening disease }\end{array}$ \\
\hline \multirow[t]{3}{*}{ Therapeutic duplication } & $\mathbf{A}$ & DOAC is the only antithrombotic \\
\hline & B & Concomitant anticoagulant when switching therapy (DOAC to VKA) \\
\hline & C & Duplication of antithrombotic \\
\hline \multirow[t]{2}{*}{ Duration of therapy } & $\mathbf{A}$ & Duration in accordance with manufacturer indications \\
\hline & C & Duration not appropriate based on recommendations \\
\hline
\end{tabular}

Notes: $\mathrm{A}=$ appropriate, $\mathrm{B}=$ inappropriate with limited clinical importance, $\mathrm{C}=$ inappropriate. $\mathrm{c} / \mathrm{o}=$ without, s/sx = signs and symptoms. ${ }^{\mathrm{L}} \mathrm{Larock} \mathrm{AS}, \mathrm{Mullier} \mathrm{F}$, Sennesael $\mathrm{AL}$, et al. Ann Pharmacother, 2014;48(I0), I258-1268, Copyright @2014 by SAGE Publications, adapted by permission of SAGE Publications.Inc.'

Abbreviations: BID, twice daily; DDI, drug-drug interaction; INR, international normalization ratio; DOAC, direct oral anticoagulant; VKA, vitamin K antagonist; VTE, venous thromboembolism.

\section{Reference}

1. Larock AS, Mullier F, Sennesael AL, et al. Appropriateness of prescribing dabigatran etexilate and rivaroxaban in patients with nonvalvular atrial fibrillation: a prospective study. Ann Pharmacother. 2014;48(10): $1258-1268$.

\section{Publish your work in this journal}

The International Journal of General Medicine is an international, peer-reviewed open-access journal that focuses on general and internal medicine, pathogenesis, epidemiology, diagnosis, monitoring and treatment protocols. The journal is characterized by the rapid reporting of reviews, original research and clinical studies across all disease areas.

\section{Dovepress}

The manuscript management system is completely online and includes a very quick and fair peer-review system, which is all easy to use. Visit http://www.dovepress.com/testimonials.php to read real quotes from published authors. 